\title{
Does a single plasma phenylalanine predict quality of control in phenylketonuria?
}

\author{
A MacDonald, G W Rylance, D Asplin, S K Hall, I W Booth
}

\begin{abstract}
A 1993 MRC working group on phenylketonuria suggested standardising blood phenylalanine measurements by taking blood samples at the same time each day. Since it is not known how representative of a 24 hour period a single phenylalanine concentration is, the aim of this study was to investigate the 24 hour variability of plasma phenylalanine in well controlled children with phenylketonuria. Sixteen subjects, 12 girls and four boys aged 1 to 18 years, had hourly venous blood samples collected for 13 hours between 09.00 and 21.00 on one day. Serial skin puncture blood specimens were then collected at $24.00,03.00$, and 06.00 within the same 24 hour period. All food and drink was weighed. The median variation in plasma phenylalanine concentration was 155 $\mu \mathrm{mol} / 1 / \mathrm{day}$, with a minimum of 80 and a maximum of 280 . The highest concentration occurred in the morning between 6.00 and 9.00 in $63 \%$ of subjects; the lowest occurred between midday and midnight in 94\%. Concentrations $<100 \mu \mathrm{mol} / 1$ occurred in $46 \%$ of children below 11 years, three having concentrations $<30 \mu \mathrm{mol} / 1$ for two, six, and seven hours respectively. Three of five subjects had concentrations above the MRC guidelines for $24 \%$ of the period studied. Except in two subjects, the blood concentrations did not rise in response to phenylalanine consumption. However, the greater the quantity of protein substitute taken between waking and the 16.00 specimen, the larger the decrease in daytime phenylalanine concentration $(r=-0.7030)(p<0.005)$. There is therefore wide variability in phenylalanine concentrations in a 24 hour period in children with phenylketonuria which is not reflected in a single observation. Further study is needed to investigate the effects of timing of protein substitute on the stability of phenylalanine concentrations.

(Arch Dis Child 1998;78:122-126)
\end{abstract}

Keywords: phenylketonuria; plasma phenylalanine; phenylalanine

Data on 24 hour variability of phenylalanine concentrations in children with phenylketonuria are lacking, but have become particularly important following a recent publication ${ }^{1}$ indicating that plasma phenylalanine should be maintained at lower concentrations and within a narrower range than previously recom- mended. Moreover, it is not known to what extent a single phenylalanine concentration taken at the same time each day is representative of an entire 24 hour period.

Guttler et al found that phenylalanine concentrations were higher in the morning than in the evening in two children with phenylketonuria aged 3 years, ${ }^{2}$ but phenylalanine was only measured at two time points on each of three consecutive days. Van Spronsen et al concluded that the daily fluctuation in plasma phenylalanine concentration was small. ${ }^{3}$ However, measurements were only taken in nine patients at 30 minute intervals for five hours from before breakfast to two hours after the midday meal.

In contrast, in a recent study of 19 children with phenylketonuria, ${ }^{4}$ we found large intrapatient variations in phenylalanine concentrations according to the timing of ingestion and distribution throughout the day of their protein substitute. However, this study was limited in that phenylalanine concentrations were measured at only two set time points within each 24 hour period. It may therefore have failed to detect considerable and therapeutically important interindividual and intraindividual variation in phenylalanine concentrations throughout the remainder of the 24 hour period. We have, therefore, investigated in detail the circadian rhythm of plasma phenylalanine in well controlled children with phenylketonuria. We aimed to identify the highest and lowest phenylalanine concentrations within a 24 hour period and to determine the length of time for which plasma phenylalanine concentrations are outside the recommended MRC working group range. $^{1}$

\section{Methods}

SUBJECTS

Sixteen patients (15 white and one AfroCaribbean) with classical phenylketonuria were recruited. There were three inclusion criteria: (1) maintenance of plasma phenylalanine concentrations (weekly, fortnightly, or monthly according to age group) within the ranges recommended by the MRC working group ${ }^{1}$ for $70 \%$ of the six months before entering the study; (2) over 1 year of age; and (3) parental ability to take skin puncture blood specimens at home by thumb prick. There were 12 girls and four boys, with a median age of 6 years (range 1 to 18 years).

The median number of $50 \mathrm{mg}$ phenylalanine exchanges allocated was six per day (range 3.5 to 18) with an equivalent median natural protein intake of $6 \mathrm{~g}$ daily. The following amounts of total protein $/ \mathrm{kg} /$ day from protein 
substitute and phenylalanine exchanges were allocated: age $<2$ years: $3.0 \mathrm{~g} / \mathrm{kg} ; 2-5$ years: 2.5 $\mathrm{g} / \mathrm{kg}$; $6-10$ years: $2.0 \mathrm{~g} / \mathrm{kg}$; over 11 years of age: $1.5 \mathrm{~g} / \mathrm{kg}$.

The brand of protein substitute used was chosen by the patient and was given either as a paste or as a drink. Nine patients used XP Maxamaid (Scientific Hospital Supplies, Liverpool), six used Phlexy 10 Drink Mix (Scientific Hospital Supplies), and one used Aminogran Food Supplement (UCB Pharma, Watford).

The study was approved by the committee on medical ethics of South Birmingham Health Authority. Informed consent was obtained from all parents and from all competent patients.

\section{ASSESSMENT OF PLASMA PHENYLALANINE}

CONCENTRATIONS

Patients attended the Children's Hospital for 13 hours during one day. Following application of topical anaesthetic cream, indwelling venous cannulas were inserted and kept open throughout the study period by intermittent insertion of heparinised saline. Blood samples for phenylalanine estimation were collected into heparinised tubes at hourly intervals from 09.00 to 21.00 inclusive. The study was continued at home through the remainder of the 24 hour period, with parents taking serial skin puncture blood specimens at midnight, 03.00, and 06.00. Blood collection technique had been taught and competence assessed by a specialist nurse. The night time blood specimens were then collected by one of us (AM) within four hours of study completion and taken to the laboratory. All the blood specimens were centrifuged upon receipt and resulting plasma samples stored at $-20^{\circ} \mathrm{C}$ until analysed. Plasma phenylalanine concentrations were measured by high pressure liquid chromatography (HPLC).

The child's usual daily activity was maintained as closely as possible during the day of the study. Children under 10 years took part in school-type activities in the morning, were entertained by a clown in the afternoon, and watched videos and television in the evening. Older patients watched videos, listened to music, and read magazines throughout the day. Children were free of intercurrent infections on the day of study.

ASSESSMENT OF PHENYLALANINE, PROTEIN

SUBSTITUTE, AND ENERGY INTAKE

Customary food intake was maintained as closely as possible on the day of study. Patients ate their usual breakfast at home before their first blood test. Packed lunches were provided, and later an evening meal similar to what they would have at home was given. All food and drink intake was documented during the study, including any taken before the first blood test of the study. Food to be eaten was weighed using Salter electronic scales (accurate to $5 \mathrm{~g}$ ), about which parents or older subjects had been instructed. Parents recorded only food and drink actually consumed; any remaining food was reweighed and deducted from the total start weight. The weighing and recording of food and drink during the day was supervised by one of us (AM). Timing and quantity of protein substitute consumed was also recorded prospectively.

Nutritional analysis of food intake was calculated using the Microdiet computer program based on McCance and Widdowson's The Composition of Foods, ${ }^{5-9}$ with supplementary analysis data provided by manufacturers and added to the database. Energy intake was calculated as a percentage of the estimated average requirement for energy. ${ }^{10}$

\section{STATISTICAL ANALYSES}

Statistical analysis was by Pearson's product moment correlation coefficient $(r)$ comparing change in phenylalanine concentrations with timing of protein substitute intake.

\section{Results}

PLASMA PHENYLALANINE CONCENTRATIONS

There was a wide variation in plasma phenylalanine concentration over the time period studied (fig 1). The median (range) variation in plasma phenylalanine concentration was 150 $\mu \mathrm{mol} / \mathrm{l} / \mathrm{day}(110$ to $220 \mu \mathrm{mol} / \mathrm{l})$ for the $1-5$ year group $(\mathrm{n}=5), 180 \mu \mathrm{mol} / \mathrm{l} /$ day $(100$ to 280 $\mu \mathrm{mol} / \mathrm{l})$ for the $6-10$ year group $(\mathrm{n}=4)$, and $170 \mu \mathrm{mol} / \mathrm{l} /$ day (80 to $220 \mu \mathrm{mol} / \mathrm{l}$ ) for the 11-18 year group $(n=7)$.

The highest phenylalanine concentration in most children occurred in the morning and $63 \%$ attained their highest level between 06.00 and 09.00 (fig 2). However, in $31 \%$ the highest concentration did not occur until after midday, and in $19 \%$ the peak occurred in late afternoon. In contrast, almost all patients had their lowest phenylalanine concentrations after midday, $63 \%$ reaching their lowest point between 18.00 and midnight (fig 2).

Phenylalanine concentrations less than 100 $\mu \mathrm{mol} / 1$ occurred in $46 \%$ of children aged 10 years or below (five of 11). The length of the time the phenylalanine concentration remained below $100 \mu \mathrm{mol} / 1$ varied from $50-77 \%$ of the 24 hour period studied. Three children had concentrations of less than $30 \mu \mathrm{mol} / 1$ for two, six, and seven hours, but in each of these the phenylalanine concentrations were over 100 $\mu \mathrm{mol} / 1$ at 09.00 . In these children, the median phenylalanine for the day was $65 \mu \mathrm{mol} / 1$. Only one child aged 10 years or under had phenylalanine concentrations above the MRC range guidelines $^{1}$ (for $27 \%$ of the period studied), but three of five subjects over 11 years had phenylalanine concentrations above the MRC guidelines for $24 \%$ of the period studied.

DIETARY INTAKE

The median (range) energy intake was $117 \%$ $(60 \%$ to $208 \%)$ of the estimated average requirement ${ }^{10}$ and was not correlated with the change in plasma phenylalanine concentrations. Phenylalanine concentrations did not rise in response to phenylalanine consumption, except in two subjects in whom peaks in phenylalanine concentrations occurred up to two hours after intake. There was a significant correlation between the timing of protein substitute and per cent change in plasma phenyl- 

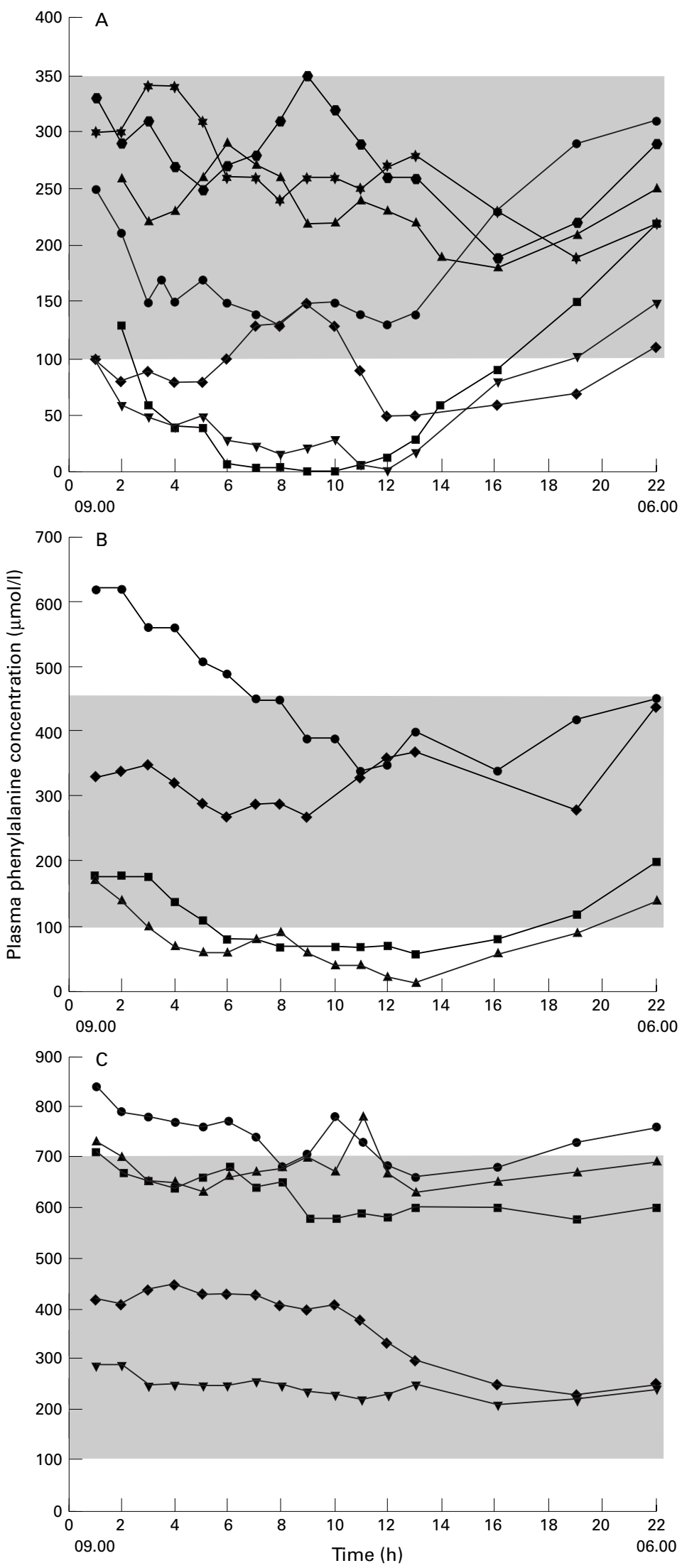

Figure 124 hour plasma phenylalanine concentrations in $(A) 1-5$ year olds $(n=7)$; (B) 6-9 year olds $(n=4)$; (C) 10-18 year olds $(n=5)$.

alanine concentrations: the greater the quantity of protein substitute consumed by the 16.00 specimen, the larger the decrease in daytime

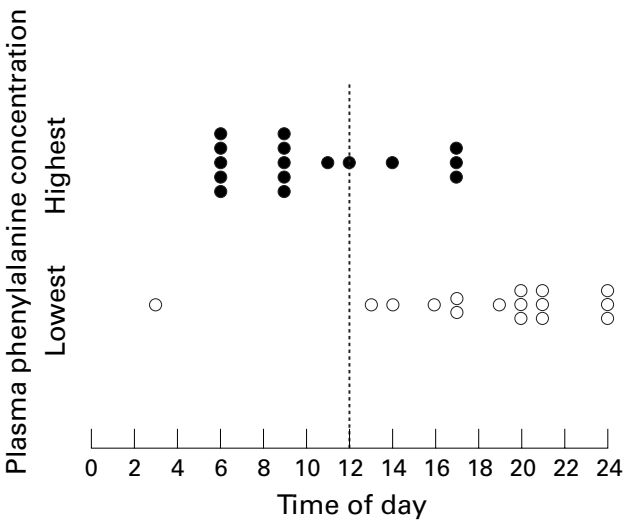

Figure 2 Highest and lowest phenylalanine concentrations in the 24 hour study period.

phenylalanine concentration $(r=-0.7030$; $\mathrm{p}<0.005)$. The less the protein substitute consumed after 16.00, the larger was the increase in plasma phenylalanine concentration between 16.00 and 06.00 the following morning $(r=-0.7337 ; \mathrm{p}<0.005)$.

\section{Discussion}

To our knowledge this is the first study to measure the variability of plasma phenylalanine concentrations throughout a 24 hour period in children with phenylketonuria. The median difference between highest and lowest concentrations observed was $155 \mu \mathrm{mol} / \mathrm{l} /$ day, with peak concentrations usually occurring before midday, and lowest in the afternoon or evening. Although only 16 patients were studied in a single 24 hour period, they represented a wide age range and all had classical phenylketonuria. For social, ethical, and practical considerations, two methods of blood sampling technique were used: venous sampling during the day and thumb skin puncture overnight. Unfortunately, although it is widely presumed there is little difference in the results between thumb skin puncture and venous sampling techniques, there are no published data to support this. However, it is likely that the quality of skin puncture analysis is influenced by operator skill, and all parents were trained and experienced at taking thumb prick blood specimens.

The wide variation seen in plasma phenylalanine concentrations was quite different from the findings in children without phenylketonuria $^{11}$ and in adults. ${ }^{12}$ The stability of amino acid concentrations in the plasma is probably the result of a combination of factors including dietary intake, release from endogenous protein stores, uptake into liver and non-hepatic tissues, and endogenous protein synthesis and catabolism. ${ }^{13}$ However, in this study the consumption of phenylalanine did not appear to cause any significant increase or peaks in phenylalanine concentrations. This is supported by a recent study by Van Spronsen $e t$ $a l,{ }^{14}$ examining changes in plasma phenylalanine resulting from different distributions of daily phenylalanine intake in phenylketonuria. These findings contrast with those in normal individuals, perhaps because patients with 
phenylketonuria have a lower intake of phenylalanine relative to plasma pool size. ${ }^{3} \mathrm{~A}$ factor which is unlikely to have an important effect is exercise, as this has not been shown to alter phenylalanine concentrations in normal adults. ${ }^{15}$

The factor probably responsible for most of the variability in phenylalanine concentrations was the uneven distribution of protein substitute. Excess administration of protein substitute at any one time appears to cause a rapid decline in phenylalanine concentration. If further protein substitute is not consumed for several hours, there is then an increase in plasma phenylalanine, probably resulting from protein catabolism and the release of amino acids into the plasma pool. Eighty two per cent $(\mathrm{n}=13)$ of all the children took the protein substitute three or more times daily, but only $44 \%(n=7)$ took it at the recommended three to four hour intervals with meals. In the latter group there appeared to be persistent depression of phenylalanine concentrations during the daytime and early evening, but increased concentrations overnight. Younger children in particular were more likely to consume the protein substitute in this way. The other $38 \%$ of the subjects $(n=6)$, mainly older patients, took a late evening dose of protein substitute. They had relatively small changes in phenylalanine concentration overnight $(-60 \mu \mathrm{mol} / 1$ to +30 $\mu \mathrm{mol} / \mathrm{l})$. Administration of protein substitute in small dosages, over a prolonged period, for example 16 hours, may stabilise plasma phenylalanine concentrations. However, this may not be practical in young children who usually sleep for longer than eight hours overnightbut it does warrant further investigation.

Our study shows that single and early morning specimens in any one 24 hour period give an incomplete and unrepresentative indication of phenylalanine control for many children with phenylketonuria. It identifies the range of time during which phenylalanine concentrations lie outside the MRC guidelines in "well controlled" children. Single point phenylalanine concentrations may be particularly misleading in the young child. If an early morning phenylalanine concentration is just above the MRC lower limit, it is considered satisfactory. But in the same child phenylalanine concentrations could be less than $100 \mu \mathrm{mol} / 1$ for a significant time during the 24 hours, particularly if the protein substitute is given evenly with the three meals daily as usually recommended. It is of particular concern that the study identified a small number of children who had phenylalanine concentrations less than $30 \mu \mathrm{mol} / 1$ for up to seven hours within a 24 hour period. Although there is no evidence that hypophenylalaninaemia is detrimental to long term neurological outcome, or that transient hypophenylalaninaemia is detrimental to intelligence quotient, it is only within the last four years in the United Kingdom that phenylalanine concentrations have been maintained within such narrow and low limits. Furthermore, a recent study from The Netherlands has shown that height $\mathrm{z}$ scores in phenylketonuric children at the age of 3 years were less than reference values. For boys, this reflected an average decrease of $30 \mathrm{~mm}$ in expected height. ${ }^{16}$ The authors hypothesised that treatment regimens aiming at maintaining lower phenylalanine concentrations may lead to adverse effects on growth. Even so, they found no direct correlation between the percentage of phenylalanine concentrations less than $120 \mu \mathrm{mol} / 1$ and poor growth, although they did not appear to correlate the actual extent to which phenylalanine concentrations fell below $120 \mu \mathrm{mol} / 1$ with growth. However, they did recognise that other periods of hypophenylalaninaemia may have remained unidentified. ${ }^{17}$

Phenylalanine concentrations only rose above the MRC working group ${ }^{1}$ upper reference ranges when subjects started with a relatively high baseline level. With the exception of one subject, this occurred in teenagers who aimed to maintain their phenylalanine concentrations between 100 and $700 \mu \mathrm{mol} / 1$. Their median variation in phenylalanine concentrations was no greater than in younger patients. However, phenylalanine concentrations over $700 \mu \mathrm{mol} / 1$ for a significant proportion of a 24 hour period may have consequences for neuropsychological performance. Short term concentrations over 800 $\mu \mathrm{mol} / 1$ have been associated with prolonged performance times on neuropsychological tests of higher integrative function. ${ }^{18} \mathrm{~A}$ phenylalanine concentration over $600 \mu \mathrm{mol} / 1$ on the day of neuropsychological testing has also been associated with a sustained attention deficit and difficulty with calculation tasks. ${ }^{18}$

In conclusion, there is wide variability in phenylalanine concentrations throughout the day in children with phenylketonuria who have acceptable early morning phenylalanine concentrations. The significance of this is unknown. Variability is probably due to consumption of total daily protein substitute within a 10 hour period, and simply adjusting the timing of its administration may lead to more stable phenylalanine concentrations. If adjusting protein substitute distribution does prove to be effective, this is preferable to advocating an increased frequency of plasma phenylalanine monitoring. The latter may be helping in trying to adjust diet treatment to obtain better phenylalanine control, but is invasive, expensive, and time consuming, and should only be considered as a final alternative.

We wish to thank Mrs Deborah Wills and Mr Russell Denmeade for their technical skills in performing the HPLC phenylalanine analyses and Dr Phillip Western for his help with the blood sampling. In addition, they wish to thank the National Society for Phenylketonuria for financial support for this study.

1 Report of Medical Research Council Working Party on Phenylketonuria. Recommendations on the dietary management of phenylketonuria. Arch Dis Child 1993;68:4267.

2 Guttler F, Olesen ES, Wainberg E. Inverse diurnal variation of serum phenylalanine and tyrosine in phenylketonuria
children on low-phenylalanine diet. In: Allan JD, Holt KS, Ireland JT, et al, eds. Enzymopenic anaemias, lysosomes and Ireland JT, et al, eds. Enzymopenic anaemias, lysosomes and
other papers. (Proceedings of the Sixth Symposium of the other papers. (Proceedings of the Sixth Symposium of the
Society for the Study of Inborn Errors of Metabolism.) Society for the Study of Inborn Errors of Metab

3 van Spronsen FJ, van Rijn M, van Dijk T, et al. Plasma phevan Spronsen FJ, van Rijn M, van Dijk T, et al. Plasma phe-
nylalanine and tyrosine responses to different nutritional 
conditions (fasting/post prandial) in patients with phenylketonuria: effect of sample timing. Pediatrics 1993 92:570-3.

4 MacDonald A, Rylance G, Hall SK, et al. Factors affecting the variation in plasma phenylalanine in patients with phenylketonuria on diet. Arch Dis Child 1996;74:412-7.

5 Holland B, Welch AA, Unwin ID, et al. McCance and Widdowson's the composition of foods. 5th Ed. Cambridge: Royal Society of Chemistry and Ministry of Agriculture, Fisheries and Food, 1991.

6 Holland B, Unwin ID, Buss DH. Fruits and nuts. Cambridge: Royal Society of Chemistry and Ministry of Agriculture, Fisheries and Food, 1991.

7 Holland B, Unwin ID, Buss DH. Vegetables, herbs and spices. Cambridge: Royal Society of Chemistry and Ministry of Agriculture, Fisheries and Food, 1991.

8 Holland B, Unwin ID, Buss DH. Milk products and eggs. Cambridge: Royal Society of Chemistry and Ministry of Agriculture, Fisheries and Food, 1989.

9 Holland B, Unwin ID, Buss DH. Cereals and cereal products. Cambridge: Royal Society of Chemistry and Ministry of Agriculture, Fisheries and Food, 1988.

10 Department of Health. Dietary reference values for food, energy and nutrients for the United Kingdom. (Report on $\mathrm{H}$ Social Subjects No 41.) London: HMSO, 1991.

11 Gregory DM, Sovetts D, Clow CL, et al. Plasma free amino acid values in normal children and adolescents. Metabolism 1986;35:967-9.
12 Scriver CR, Gregory DM, Sovetts D, et al. Normal plasma free amino acid values in adults: the influence of some
common physiological variables. Metabolism 1985;34:86873 .

13 Scriver CR, Clow CL, Lamm P. Plasma amino acids: screening, quantitation, and interpretation. Am f Clin Nutr 1971;24:876-90.

4 van Spronsen FJ, van Rijn M, van Dijk, et al. Phenylketonuria: plasma phenylalanine responses to different distributions over the day of the daily phenylalanine allowance. Pediatrics 1996;97:839-44.

15 Devlin JT, Brodsky I, Scrimgeour A, et al. Amino acid metabolism after intense exercise. Am f Physiol 1990;258: E249-55.

16 Verkerk PH, van Spronsen FJ, Smith GPA, on behalf of the National PKU Steering Committee. Impaired prenatal and postnatal rowth in Dutch patients with phenylketonuria. postnatal growth in Dutch patients with phenylketonuria.

van Spronsen FJ. Phenlketonur

7 van Spronsen FJ. Phenylketonuria: implications of some biochemical and clinical findings. Groningen: University of Groningen, 1996:39-53.[Thesis.]

18 Krause W, Halminski M, McDonald L, et al. Biochemical and neuropsychological effects of elevated plasma in patients with treated phenylketonuria. $\mathcal{f}$ Clin Invest 1985;75:40-8.

19 de Sonneville LMJ, Schmidt E, Michel U, et al. Preliminary neuropsychological test results. Eur $\mathcal{f}$ Pediatr 1990; 149(suppl 1):S39-44. 